\title{
The Butterfly Dream and Zhuangzi's Perspectivism: An Exploration of the Differing Interpretations of the Butterfly Dream against the Backdrop of Dao as Pluralistic Monism
}

Christine Abigail L. Tan

\begin{abstract}
The Butterfly Dream is probably one of the most well-known anecdotes in philosophical literature, and as such, it has both enjoyed and suffered from several interpretations and misinterpretations. There are much more interpretations of the Butterfly Dream than this study can gloss over, but for the sake of brevity: I divide the two approaches according to how they view the characters in the plot. Specifically speaking, the first group, which for convenience I will call the egoistic thesis, views the plot in such a way that Zhuangzi is Chuang Chou, and that the butterfly is an imagined representation of the mind, while the second group, which for convenience I will call the monistic thesis, holds that Zhuangzi is different from Chuang Chou as well as the butterfly, hence supposing that the butterfly dream is an entirely distinct reality. Albeit seemingly crude, this provides a simple yet insightful view of the premises that prevent one approach from compromising with the other, as well as the crossing over of one interpretation into another which belong to the same approach. Moreover, this approach will allow me to better fulfill the overarching aim of this study, which is to contextualize a specific rendition of the monistic thesis against the backdrop of the philosophy of the Inner Chapters and its notion of Dao as a whole such that the Zhuangzi will emerge more aptly as a perspectivist. In other words, the Butterfly Dream points to what Hans-Georg Moeller terms as "a structure of presence" which, if viewed against the context of Zhuangzi's philosophy, shows the paradox of the absolute unity but also the absolute singularity of all things.
\end{abstract}

Keywords: Zhuangzi, Daoism, pluralistic monism, butterfly dream,

(c) 2016 Christine Abigail L. Tan

http://www.kritike.org/journal/issue_19/tan_december2016.pdf

ISSN 1908-7330 
In what were earlier times,

Chuang Chou dreamed, making a butterfly.

So flitted, flitted, he was a butterfly.

Indeed, he showed what he himself was, going as he pleasantly intended!

He did not understand Chou.

So suddenly, he awoke.

Then so thoroughly, thoroughly, it was Chou.

(But then he did) not understand

did the dream of Chou make the butterfly?

Did the dream of the butterfly make Chou?

Chou with the butterfly

there must-be, then, a division.

This it is which men call 'things changing'. ${ }^{1}$

7 The Butterfly Dream is probably one of the most well-known anecdotes in philosophical literature, and as such, it has both enjoyed and suffered from several interpretations and misinterpretations. There are much more interpretations of the Butterfly Dream than this study can gloss over, but though each interpretation is different in its own regard, much of the dialogue surrounding the anecdote can be divided into two schools. Although many interpretations divide the schools into several groups according to claim, I find this strategy not only untenable with regard to the nuances in detail, but also highly confusing and complex; as such, my division is simple: I divide the two approaches according to how they view the characters in the plot. Specifically speaking, the first group, which for convenience I will call the egoistic thesis, views the plot in such a way that Zhuangzi is Chuang Chou, and that the butterfly is an imagined representation of the mind; while the second group, which for convenience I will call the monistic thesis, holds that Zhuangzi is different from Chuang Chou as well as the butterfly, hence supposing that the butterfly dream is an entirely distinct reality. Albeit seemingly crude, this provides a simple yet insightful view of the premises that prevent one approach from compromising with the other, as well as the crossing over of one interpretation into another which belong to the same approach. Moreover, this approach will allow me to better fulfill the overarching aim of this study, which is to contextualize a specific rendition of the monistic thesis against the backdrop of the philosophy of the Inner Chapters and its notion of Dao as a whole such that the Zhuangzi will emerge more aptly as a perspectivist. ${ }^{2}$

\footnotetext{
${ }^{1}$ Kuang-Ming Wu, The Butterfly as Companion: Meditations on the First Three Chapters of the Chuang Tzu (Albany, NY: State University of New York Press, 1990), 153. I chose this translation because it is the closest, word per word, to the Chinese free-verse.

${ }^{2}$ Perspectivism here is to be distinguished from the notion that truth is relative, as in relativism, but rather that the relative is true, and is an angle of the bigger picture.
} 
In order to do this, I will first discuss the contention of the egoistic thesis, championed by Robert Allinson among others, and show why this interpretation is problematic in such a way that it gives more importance to one reality, whether the dream or waking reality, over the other, and as such, undermines the position of Zhuangzi as a perspectivist. In contrast then, I will discuss the contention of the monistic thesis, specifically picking out that of Hans-Georg Moeller's as well as Kuang-Ming Wu's as two sides of the same coin that is pluralistic monism, and show that these two are the most apt interpretations of the Butterfly Dream when placed against the backdrop of Zhuangzi's philosophy as seen in Inner Chapters and his perspectivism. Finally, I support the latter thesis further by looking at the different angles of Zhuangzi's philosophy which show him as a perspectivist, from which we can conclude that the Butterfly Dream points to a structure of presence ${ }^{3}$ which, if viewed against the context of Zhuangzi's philosophy, shows the paradox of the absolute unity but also the absolute singularity of all things. That is to say, that both the butterfly and Chou are singular in their very existence, but both are, essentially, united in Zhaungzi the narrator, in the same way that the Dao, though unknowable in its totality, is manifested in singularities as a never-ending process of becoming which Zhuangzi calls the "transformation of things." 4

\section{The Egoistic Thesis}

There are several renditions of the egoistic thesis but the common denominator, as previously mentioned, is that it views the dream as a representation, and the butterfly as an image of that representation. There are basically two kinds of this thesis, and one views the butterfly dream as more important, while the other views waking reality as more important. The former variant has renditions that regard the butterfly as a symbol of Dao as in Jung H. Lee, ${ }^{5}$ as a mere image which provides the opportunity to doubt one's waking reality, radicalizing the Cartesian doubt, as in Xiaoqiang Han, ${ }^{6}$ or as the Cartesian cogito itself as discovered in the Jungian unconscious as

\footnotetext{
${ }^{3}$ Hans-Georg Moeller, "Zhuangzi's 'Dream of the Butterfly': A Daoist Interpretation," in Philosophy East and West, 49:4 (1999), 439-450.

${ }^{4}$ Chuang Tzu, "Discussion on Making All Things Equal," in The Complete Works of Chuang Tzu, trans. by Burton Watson, in Terebress Asia Online (TAO), <http://terebess.hu/english/chuangtzu.html\#2>, 13 November 2014.

${ }^{5}$ Jung H. Lee, "What Is It Like to Be a Butterfly? A Philosophical Interpretation of Zhuangzi's Butterfly Dream," in Asian Philosophy, 17:2 (2007), 185-202.

${ }^{6}$ Xiaoqiang Han, "Interpreting the Butterfly Dream," in Asian Philosophy, 19:1 (2009), $1-9$.

(c) 2016 Christine Abigail L. Tan http://www.kritike.org/journal/issue 19/tan december2016.pdf ISSN 1908-7330
}

(c) BY-NC-ND 
Zhihua Yao, ${ }^{7}$ among other specific interpretations. The former variant of the egoistic thesis, which seems to be fashioned in a more sophisticated and logical manner is that which regard the enlightenment of waking reality as more important; this variant is the one championed by Robert E. Allinson, who argues that the generally accepted ordering of events in the Qiwulun is illogical, leading to incoherent interpretations. That is, Allinson thinks that the Great Sage/Great Awakening story should come after the Butterfly Dream instead of preceding it, in order to present the progress in the plot of the chapter.

Nevertheless, the contention of this study is that, looking at it from the view of the egoistic thesis can be problematic when placed against the backdrop of Zhuangzi's perspectivism. It should be noted, however, that although an objection can be made by claiming that I am trying to set up a strawman for these philosophers as they never said that Zhuangzi is a perspectivist nor tried to prove it, it is worthwhile to understand that this study is merely providing insight on the plethora of interpretations if we are to consider Zhuangzi as a perspectivist, which we will also later try to discuss in the third section of this paper, with the Butterfly Dream itself as the vehicle.

In order to better show this, we will take a look at the several renditions of the egoistic thesis.

\section{The Butterfly as a Symbol of the Dao}

Jung H. Lee, in his article "What is it Like to be a Butterfly? A Philosophical Interpretation of Zhuangzi's Butterfly Dream," maintains that the butterfly is nothing more than a symbol of the Dao, over and above the message that nothing is absolute in this world-guided by his choice of translation, which is that of A.C. Graham:

Last night Zhuang Zhou dreamed he was a butterfly, spirits soaring he was a butterfly (is it that in showing what he was he suited his own fancy?), and did not know about Zhou. When all of a sudden he awoke, he was Zhou with all his wits about him. He does not know whether he is Zhou who dreams he is a butterfly or a butterfly who dreams he is Zhou. Between Zhou and the

7 Zhihua Yao, “'I Have Lost Me': Zhuangzi's Butterfly Dream," in Journal of Chinese Philosophy, 40:3-4 (2013), 511-526. 
butterfly there was necessarily a dividing; just this is what is meant by the transformation of things. ${ }^{8}$

The third-person perspective is used here to denote the distanced uncertainty present in the voice, leading Lee to a kind of withdrawn relativistic approach to the text. Lee says that in the same way that the views of philosophers such as the Mohists and the Confucians come and go, to regard himself as the Butterfly is the same thing that Mohists and Confucians do when they insist, and hence absolutize, on what they think is true or right. ${ }^{9}$ Lee notes that:

Thus, at one level, Zhuangzi is recommending a stance of epistemic humility and an acceptance of the plurality of perspectives that populate the state of Nature. Our aspirations for global comprehensiveness must be tempered as we try to appreciate competing perspectives. This would be what I would call the epistemic imperative of the passage.

At a second level, I think we must look at the butterfly as a normative ideal that embodies many of the qualities and virtues of the Way itself. This use of a natural metaphor should come as no surprise since most ancient Chinese philosophers assume that common principles inform both the natural and human worlds and that it is by reflecting the patterns and processes of the cosmos that we realize the Good. ${ }^{10}$

On one level, however, it seems to reduce philosophy into wisdom, that is, life advice, and then, on another, undermines the butterfly dream as a mere symbol-a signifier; a tool, which does not possess its entirely distinct, and own, reality, and yet leads us to doubt the reality which we are in. In other words, the butterfly dream is treated for what it is, a dream, à la Thomas Nagel's "What Is It Like to Be a Bat?" 11 wherein one retains the human

8 A.C. Graham, Chuang-tzu, The Seven Inner Chapters and Other Writings from the Book Chuang-tzu. (London: George Allen and Unwin, 1981), 61. Cf. Lee, "What Is It Like to Be a Butterfly?", 185.

${ }^{9}$ Lee, “What Is It Like to Be a Butterfly?", 196.

${ }^{10}$ Ibid., 198.

${ }^{11}$ Nagel argues that for us to imagine what it is like to be a bat, we may try to do the things a bat normally does as per our studies of the composition of the bat, but never what it is like to for an actual bat to be a bat. In other words, one consciousness is entirely unique from the other, and when one tries to analyze or to imagine being in another's shoes, the personal self 
faculties despite trying to imagine what it would be like to be a bat, or a butterfly for that matter.

\section{The Butterfly Dream as an Image for Radical Skepticism}

In contrast, though in the same vein, Xiaoqiang Han, in his article "Interpreting the Butterfly Dream," takes the butterfly dream to be a kind of meditation, à la Descartes' Cogito Ergo Sum, which radicalizes the Cartesian doubt, allowing Zhuangzi to doubt that which for Descartes was indubitable, that "I exist." Han's interpretation allows him to formulate his own interpretation, which is largely guided by that of Herbert Giles, ${ }^{12}$ with the exception of omitting "a man" (replacing it with Zhuangzi) as well as the term Metempsychosis, but more importantly, the italicized in the following:

Once upon a time, I, Zhuangzi, dreamed I was a butterfly, fluttering hither and thither, to all intents and purposes a butterfly. I was conscious only of following my fancies as a butterfly, and was unconscious of my individuality as a man. Suddenly, I awaked, and there I lay, myself again. Now I do not know whether I was then Zhuangzi dreaming I was a butterfly, or whether a butterfly is now dreaming it is me. Between Zhuangzi and a butterfly there is necessarily a barrier. This is called transformation of things. ${ }^{13}$

The italicized text is, in Giles translation: "or whether I am now a butterfly, dreaming I am a man." Although Han retains the first-person perspective, for the reason that even though the word "I" is absent in the original text, classical Chinese authors referred to themselves in their own names as a style of modesty making the inclusion of "I" permissible, Giles' translation still nevertheless presupposes a dreamer, the "I" as the real and substantial man, and the dream where the butterfly is an image which leads

regardless of any claim to objectivity necessarily and subjectively biases it. See Thomas Nagel, “What Is It Like to Be a Bat?" in The Philosophical Review, 83:4 (1974), 435-450.

12 "Once upon a time, I, Chuang Tzu [Zhuangzi], dreamt I was a butterfly, fluttering hither and thither, to all intents and purposes a butterfly. I was conscious only of following my fancies as a butterfly, and was unconscious of my individuality as a man. Suddenly, I awaked, and there I lay, myself again. Now I do not know whether I was then a man dreaming I was a butterfly, or whether I am now a butterfly, dreaming I am a man. Between a man and a butterfly there is necessarily a barrier. The transition is called Metempsychosis." See Chuang Tzu, Chuang Tzu: Taoist Philosopher and Chinese Mystic, trans. by Herbert A. Giles (London: Unwin Paperbacks, 1926), 47. Cf. Han, "Interpreting the Butterfly Dream."

${ }^{13}$ Han, "Interpreting the Butterfly Dream," 5. Emphasis mine.

(C) 2016 Christine Abigail L. Tan

http://www.kritike.org/journal/issue 19/tan december2016.pdf

ISSN 1908-7330

(cc) BY-NC-ND 
to the "I" doubting the reality where "I" am in, posing no challenge to the cogito ergo sum proof. Thus, he radicalizes this, and concludes that: "The role of the butterfly in the episode, it may be thought, is nothing more than describing a situation in which I can doubt the existence of myself." 14 This implies that for Han, Zhuangzi's butterfly may just as well be an image, dreaming of the image of Zhuangzi, that is, images within images. I wonder whether we are all just dreams within dreams with no dreamer, shifting the question of which reality is true, to whether there even is a reality in there to begin with.

Although this may be a fruitful contribution to Cartesian discourse, it is an unfair treatment of Zhuangzi, reducing him to a radical skeptic, a flatout relativist, which is not Daoist at all, as we will later elaborate more on.

\section{The Butterfly as the Symbol of the Human Soul in the Two-tiered Self}

Zhihua Yao takes a more interdisciplinary approach in his article "'I Have Lost Me:' Zhuangzi's Butterfly Dream," and calls his interpretation the self-alienation hypothesis. Basically, Yao finds the Cartesian cogito in the Jungian unconscious, and looks at the world of the butterfly as an enlightening grain of truth about one's self, as shaped by the collective unconscious of Jung. ${ }^{15}$ As such, and like Lee, Yao maintains that the butterfly is a very important symbol in Zhuangzi's dream, which can lead to a better understanding of ourselves, although he takes into consideration not only the philosophical heritage of Daoism but also its religious angle and goes on to consult psychology in his pursuit of understanding as well.

Yao takes "transformation of things" or "things changing" at the last sentence of the dream of the butterfly to mean alienation, that is, rather than external things, Yao focuses on Zhou and the butterfly other an object or a thing. Yao uses the psychology of Jung to explain this:

14 Ibid., 7.

15 On the collective unconscious, Jung says that "the existence of the collective unconscious means that individual consciousness is anything but a tabula rasa and is not immune to predetermining influences. On the contrary, it is in the highest degree influenced by inherited presuppositions, quite apart from the unavoidable influences exerted upon it by the environment. The collective unconscious comprises in itself the psychic life of our ancestors right back to the earliest beginnings. It is the matrix of all conscious psychic occurrences, and hence it exerts an influence that compromises the freedom of consciousness in the highest degree, since it is continually striving to lead all conscious processes back into the old paths." See C.G. Jung, The Structure and Dynamics of the Psyche, vol. 8 of The Collected Works of C.G. Jung, $2^{\text {nd }}$ ed. (London: Routledge, 2002), $\mathbb{1} 320$. In other words, in this sense, the butterfly is nothing more than a culturally-shaped view of what it would symbolize - a metaphor just as with mythologies and legends.

(c) 2016 Christine Abigail L. Tan

http://www.kritike.org/journal/issue 19/tan december2016.pdf

ISSN 1908-7330

(c) $\mathrm{BY}-\mathrm{NC}-\mathrm{ND}$ 
In a Jungian view, the butterfly would be the self that manifests in the dreaming state and Zhou the ego of the waking state. Butterfly and Zhou, being two selves, seem to have their own territories, and this is what Zhuangzi means by fen 分 or division. It is not a division among things, but between selves. Meanwhile, each self tries to expand its territory by projecting or objectifying its counterpart. This is what I call "self-alienation."16

In other words, Yao views the butterfly as a symbol of another tier of the self which we could look at to help us explore more about the dim passageways of our inner selves. Although this seems to be a plausible interpretation, it should be noted that Zhuangzi's point was never simply about the self, although he was of course, concerned with man's rational psychology as well. Daoism in general, especially Zhuangzi, however, dealt mostly with problems in metaphysics. ${ }^{17}$ Indeed in the very same chapter as the butterfly dream that is the Qiwulun, we find the problem raised to a more metaphysical level, encompassing a wider horizon than the self, in the Great Sage dream anecdote:

He who dreams of drinking wine may weep when morning comes; he who dreams of weeping may in the morning go off to hunt. While he is dreaming he does not know it is a dream, and in his dream he may even try to interpret a dream. Only after he wakes does he know it was a dream. And someday there will be a great awakening when we know that this is all a great dream. Yet the stupid believe they are awake, busily and brightly assuming they understand things, calling this man ruler, that one herdsman-how dense! Confucius and you are both dreaming! And when I say you are dreaming, I am dreaming, too. Words like these will be labeled the Supreme Swindle. Yet, after ten thousand generations, a great sage may appear who will know their meaning, and it will still be as though he appeared with astonishing speed. ${ }^{18}$

${ }^{16}$ Yao, “Zhuangzi's Butterfly Dream," 520.

${ }_{17}$ One simply need not look further from the Inner Chapters to see that the central themes revolve around the notion of truth, of the nature of things and of the world, and man's limited epistemological capabilities.

${ }^{18}$ Chuang Tzu, "Discussion on Making All Things Equal."

(C) 2016 Christine Abigail L. Tan http://www.kritike.org/journal/issue 19/tan december2016.pdf ISSN 1908-7330 
More on this passage, however, will be discussed in the latter part of this section as well as the next section.

Thus far, we have seen three of the same variant of the egoistic hypothesis that hold the butterfly dream as more important or favors the butterfly dream over waking reality. But there is another variant of the egoistic thesis, which seems to be of Buddhist influence, placing great importance to the notion of awakening or enlightenment. The most wellknown for this, and perhaps the only one who holds this idiosyncratic interpretation boldly enough to suggest a re-arrangement of the events in the original text, is Robert E. Allinson.

\section{The Butterfly Dream as an Illusion from which The Sage is Awakened}

Allinson, like many others, take the butterfly to be a symbol as well, but rather than zeroing in on the virtues that the butterfly seems to espouse with regard to the Dao, he chooses to focus on its capability for change towards something beautiful, that is, metamorphosis.

Indeed, for Allinson, when Zhuangzi talks about change or transformation, it should necessarily be towards something higher, not a regression as in what he calls the confusion hypothesis, where Zhou is led from certainty to uncertainty, or an existential relativism as in the endless transformation hypothesis, where the butterfly dream is made to signify the endless transformation of all things, and how one things necessarily becomes another in a never-ending process. Allinson, however, believes that, like the butterfly's transformation from a mere cocoon to a beautiful butterfly, the self in the butterfly's dream state can also progress to transform into the awakened sage. He explains:

As I have indicated in the previous chapter, I take the butterfly dream story to be an analogy of the enlightenment experience. The enlightenment experience, or the experience of illumination, is the phenomenological correlate of what I take to be the central objective of the Chuang-Tzu, that of selftransformation. It is not only the phenomenological correlate; it is the essential precondition for selftransformation. ${ }^{19}$

\footnotetext{
${ }^{19}$ Robert E. Allinson, Chuang-Tzu for Spiritual Transformation: An Analysis of the Inner Chapters (Albany, NY: State University of New York Press, 1989), 79

(c) 2016 Christine Abigail L. Tan http://www.kritike.org/journal/issue 19/tan december2016.pdf ISSN 1908-7330

(cc) BY-NC-ND
} 
Allinson thus suggests that the translation and arrangement of the text should be as follows, if we are to follow his logical interpretation:

Once upon a time, Chuang Chou dreamed he was a butterfly; flitting and fluttering he darted wherever he wanted;

he did not know he was Chuang Chou.

In fact, he didn't know if he were Chuang Chou dreaming

that he was a butterfly or a butterfly dreaming he was

Chuang Chou.

Suddenly he awakens.

He sees that he is Chuang Chou.

So, there must be a distinction between Chuang Chou and

a butterfly;

this is transformation! ${ }^{20}$

According to Allinson, the only reason why we fail to understand the butterfly dream for what it truly is, is because of the Gio Xiang redacted text where Guo Xiang, one of (if not the) foremost commentators of the Zhuangzi, adds his own philosophy into what we now know as the Zhuangzi. Thus, Allinson suggests such re-arrangement of the events in the story; but he proposes another alternative: to take another parable in the chapter that is the Great Sage dream and place it after the butterfly dream such that it becomes the precursor to the Great Sage dream which is capable of completing and explaining the butterfly dream more coherently.

If we take the Great Sage dream anecdote as the later argument logically speaking, it has the power of explaining the butterfly dream; but the reverse is not the case. Once fully awakened, one may distinguish between what is a dream and what is reality. Before one has fully awakened, such a distinction is not even possible to draw empirically. ${ }^{21}$

Allinson explains this re-arrangement of anecdotes in the chapter further:

${ }^{20}$ Ibid., 82.

${ }^{21}$ Ibid., 104-105.

(c) 2016 Christine Abigail L. Tan http://www.kritike.org/journal/issue 19/tan december2016.pdf ISSN 1908-7330 
If one is forced to choose between an interpretation of the butterfly dream anecdote as betokening an inescapable unknowingness and the Great Sage dream anecdote as being a harbinger of potential explicability, then I would choose the Great Sage dream anecdote. Under these interpretations of the dream anecdotes, both of the dream anecdotes cannot be true at the same time. If the butterfly dream anecdote is true, then the Great Sage dream anecdote is false. If the Great Sage dream anecdote is true, then the butterfly dream anecdote is false. However, we need not make such a choice. If we take the interpretation that the butterfly dream anecdote is a foreshadowing and a premature version which is better rendered in the Great Sage dream anecdote, then both dream anecdotes can be seen as consistent with each other and both can be taken as true. $^{22}$

Athough Allinson's logic seems to be well and good, and thoroughly argued, he nevertheless seems to be informed by the traditional western metaphysics of old, guided by the principle of non-contradiction, rather than Zhuangzi's Daoist logic, where being and non-being, knowing and not knowing can both be at the same time.

Indeed, this is where the egoistic hypothesis fails, in that it presupposes the falsity of the other, or at the very least, that the other is less true because one is affirmed. Awakening or doubting, the egoistic hypothesis pre-supposes an affirmed "I" within the picture, which the original text lacks.

So, what, after all, is a more plausible way to approach the butterfly dream if we are to consider the Daoist logic of the Inner Chapters? Let us now look at what I call the monistic hypothesis.

\section{The Monistic Hypothesis}

There are two prevalent commentators of the monistic hypothesis whom I wish to discuss in this section: Hans-Georg Moeller and Kuang-Ming $\mathrm{Wu}$. Although these two interpretation don't seem to resemble each other at face value, we will later on see that they arrive at the same conclusion, as they both draw from the Guo Xiang commentaries, as well as Daoist thought, to guide their interpretation of the butterfly dream.

22 Ibid., 109-110.

(c) 2016 Christine Abigail L. Tan

http://www.kritike.org/journal/issue 19/tan december2016.pdf

ISSN 1908-7330

(c) $)$ BY-NC-ND 
Moreover, I call this the monistic hypothesis because considering Zhuangzi as different from the proper name and character Chuang Chou in the story as well as the butterfly, and finding in each one an existence of their own, kept in balance by a central void, necessarily implies a kind pluralistic monism which can actually be seen in the Guo Xiang commentaries.

In this section, I chose to discuss Moeller first, who claims that his interpretation is simply a rehearsal of Guo Xiang's, because his take on the Butterfly Dream provides for us a good transitioning ground from which we can take off to Kuang-Ming Wu's more comprehensive and in-depth approach to the butterfly dream.

\section{Hans-Georg Moeller's Structure of Presence}

In "Zhuangzi's 'Dream of the Butterfly': A Daoist Interpretation," Moeller's maintains that, instead of the butterfly dream teaching the vanity and uselessness of distinctions, it is actually more the case that the butterfly dream teaches the importance of distinctions. This take is based on the classical commentary by the Daoist Guo Xiang, who thought that just as the butterfly did not know anything about Zhou, Zhou as well did not know anything about the butterfly. ${ }^{23}$ For Guo Xiang, Moeller notes:

There is no continuous substance underlying the different stages of dreaming and being awake. He points out, rather, referring to the original text, that "at its time, everything is completely in accord with its intentions. That is to say that during the time of the butterfly is no one else but the butterfly without any qualities of some "Zhuang Zhou" or even some "I," just as when awake Zhuang Zhou-whether before or after the dream-is nothing but Zhuang Zhou himself and does not have anything to do with a butterfly or with some strange " $\mathrm{I}$ " connecting him with butterflies. ${ }^{24}$

Rather, Moeller maintains that both stages, both the dream and the waking reality of Zhou, are real to the same degree. Thus, there is no "transformation" in the strict sense here, where a certain substance persists. The story, for Guo Xiang, ends in perfect certainty or doubtlessness.

\footnotetext{
${ }^{23}$ In the translations of Giles, Legge, or Graham, this does not seem to be the case. But notice how Kuang-Ming Wu's word per word translation in the beginning of this paper encloses the critical words in parenthesis. Moeller offers his own translation which basically replaces the words "but then he did" in the parenthesis to "one does."

${ }^{24}$ Moeller, "Zhuangzi's 'Dream of the Butterfly'," 440-441.
} 


\section{THE BUTTERFLY DREAM AND ZHUANGZI'S PERSPECTIVISM}

Moreover, he likens the relation between being awake and dreaming to life and death, in such a way that each has its own realm, for what belongs to life is alive and what belongs to death is dead-certainly, there is a distinction between the two, which is precisely why it is wrong to worry about death when we are alive, for what is present is in complete accord with its intentions. Further, Guo Xiang reminds us that since this is said from Zhou's perspective, awakening does not, by any means, falsify the dream. Zhou's awakening therefore, does not have the quality which Allinson imposes on it, being that of awakening from illusion to reality, and is different from the "great awakening" in the Great Sage dream which is an awakening from both reality and dreaming. ${ }^{25}$

That said, Moeller concludes that the interpretations and understanding of the butterfly dream following Giles' translation where the "II" and hence remembering and doubt, is central "contradict the notions of forgetfulness and doubtlessness that are central to Guo Xiang's," ${ }^{26}$ which is the Daoist approach to the butterfly dream. Moeller explains:

The Daoist idea is not that of a bridge constituting a process of change, and constituted by something that would continuously accompany all segments. It is rather the idea that a sharp "distinction)" (fen 分) between the segments of a process is the basis for the equal authenticity of each segment. ${ }^{27}$

In other words, what makes each segment completely in accord with its intentions is not that there are no distinctions, but that they have sharp distinctions, unique to themselves. Moeller continues:

What is Daoistic is not the blurring of the borderlines between the segments, between (the two) Zhuang Zhou(s) and the butterfly, between being awake and dreaming, between life and death, nor the doubts about one's real "I," but rather the belief that the authenticity are not connected to each other by any continuous bridge between them. It is un-Daoistic to believe that life and death are about the same and not clearly divided from each other: rather, life and death are as different, from the Daoist point of view, as they can possibly be. ${ }^{28}$

\footnotetext{
${ }^{25}$ Ibid., 442

${ }^{26}$ Ibid.

${ }^{27}$ Ibid., 443.

${ }^{28}$ Ibid.
}

(c) 2016 Christine Abigail L. Tan

http://www.kritike.org/journal/issue 19/tan december2016.pdf

ISSN 1908-7330

(c) $)$ BY-NC-ND 
What is for Guo Xiang to be completely in accord with its intentions, Moeller calls as the pattern which is "the structure of presence," expressed in the butterfly dream when the butterfly in the dream is in complete accord with itself. "Presence" here is to be understood as meaning that whatever is at the moment, is just what it is, and nothing else; a process, therefore, is constituted by present segments which are what they simply are without the slightest split, and yet are part of continuous and ongoing processes. In this way, Moeller notes:

It is of crucial importance for the whole process that no segment violates the distinctions between segments. To overstep one's borderline is to violate one's presence. If we start to remember or to doubt, if we start to split out "identity" by pondering on what "we" "are," and if, while being alive, we start to worry about death, we leave our total "presence" - we violate our present "identity." If, while awake, we ponder our dreams, as soon as we start to "reflect," we are no longer perfectly present. When one oversteps the limits of one's momentary segment, when one does something at the wrong or at the wrong place, one not only does harm to oneself but also brings disorder to the sequence of segments and thereby endangers the order of the whole process. In short, one acts in disaccord with Dao. ${ }^{29}$

Again, none of the parts or segments is thus inauthentic for they are all singular in their very presence, and this singularity is what keeps them in unity as a process, just as ziran ${ }^{30}$ or spontaneity is kept in balance by weiwuwei ${ }^{31}$ or creative non-action, Moeller maintains that "the realm of presence is held together non-presence," 32 and that this empty non-present is what is holding together all the present segments, wholly distinct from each

\footnotetext{
${ }^{29} \mathrm{Ibid} ., 444$.

${ }^{30}$ An important Daoist concept that means that in order to be in accord with the Dao, one must follow one's own nature. Laozi, trans. Addis and Lombardo, Tao Te Ching (Indianapolis: Hackett Pub. Co., 1993). Laozi, Tao Te Ching, trans. by Stephen Addis and Stanley Lombardo (Indianapolis: Hackett Pub. Co., 1993).

${ }^{31}$ Complementary to the concept of ziran, weiwuwei is also a central concept to Daoism which means that in order to be in accord with the Dao, one must act by not acting, that is, to not go beyond one's own nature, and to simply let the flow of nature guide one's acts. See Laozi, Tao Te Ching.

${ }^{32}$ Moeller, "Zhuangzi's 'Dream of the Butterfly'," 444.
}

(C) 2016 Christine Abigail L. Tan http://www.kritike.org/journal/issue 19/tan december2016.pdf ISSN 1908-7330 
other, from the center. Thus, "the continuous process of the segments revolves around non-presence." 33

In the butterfly dream, this non-presence in the midst of present segments is manifested by Zhuagzi, the narrator, who does not identify with any of the characters in the story, and who has forgotten himself, but remains equally close in radius to all the segments in its position as the central point. In other words, Zhuangzi, the narrator is not attached to any definite present, losing himself in the midst of the present. In contrast to Allinson, Moeller suggests that:

The sage has no sort of "higher knowledge"; he is not entitled in that sense of the word: he has rather achieved the "no-knowledge" of the "great awakening." The "great awakening" awakens from both dreaming and being awake and enters non-presence in the midst of presence. ${ }^{34}$

In other words, the Daoist structure of presence as illustrated in the butterfly dream is a well-ordered process constituted by present, and entirely distinct, segments kept in balance by a non-present center. Giles' version, therefore, as well as the previous interpretations we have discussed, leave the realm of presence and starts to enter the realm of re-present-ation by reflecting on one's self, and "having left presence he is even further separated from the realm of forgetfulness, from the non-present realm Zhuangzi, the narrator. Giles' Zhuang Zhou, it seems, has in fact 'never heard of the changing of things." 35

\section{Kuang-Ming Wu's Participatory Knowledge}

Kuang-Ming Wu's take on the first three books of the Inner Chapters is perhaps the most comprehensive and in-depth one, guided by the Guo Xiang commentaries, his language becomes a little confusing at face-value because it is very directly Eastern, but the point stands the same in the monistic hypothesis. Wu highlights the truths found in ironies and paradox, focusing on the central non-presence which lack any distinction (such differing explanation may look seemingly different in interpretation from Moeller, but conveys the same hypothesis), but continuously reminds us of the singularities of each experience. Regarding the butterfly dream he notes that:

$$
\begin{aligned}
& { }_{33}^{3} \text { Ibid. } \\
& { }^{34} \text { Ibid., } 445 . \\
& { }^{35} \text { Ibid., } 446 .
\end{aligned}
$$

(c) 2016 Christine Abigail L. Tan

http://www.kritike.org/journal/issue 19/tan december2016.pdf

ISSN 1908-7330

(c) BY-NC-ND 
In this story we see not one but two dreams, which are produced by reflecting on one dream after having been awakened from it. These two dreams are Chuang Tzu dreaming and the butterfly dreaming, and they are found to be interconnected though mutually exclusive. We usually suppose dream to be something unreal, but we seldom note that dream is also a distinct world in itself made by the dreaming subject. And the verdict on this constructed world to be "dream" is made not from inside that world (while we are dreaming) but from outside of it, realizing that we have now been "awakened" from that particular dream. And then we find that each dream is a world in itself, each different from all others. The world of the butterfly differs from that of Chuang Tzu, each with its own integrity, and he/it cannot have both at once. ${ }^{36}$

Initially, we see the difference with Moeller and $\mathrm{Wu}$, being that for Moeller, Zhuangzi is entirely out of the picture, Zhou is the same Zhou who dreams and wakes up, while Zhuangzi is a non-presence, while with $\mathrm{Wu}$, the Zhou who dreamt is different from the Zhou who woke up rather than a narrator. With $\mathrm{Wu}$, a shift in characters occur, making two dreams. Zhou, entirely distinct from the butterfly, the butterfly, entirely distinct from Zhou, but the Zhou who wakes up is the empty middle who does not identify with either. Wu goes on:

Here the distinct identities of the butterfly and the Chuang Chou have to hold. These two dreams are distinct; one cannot dream both at once. Besides, dreaming implies a dreamer, and two non-consecutive dreams imply two dreamers. They are real and distinct, and cannot be a matter of relativistic indifference. At the same time, there is an endless change-over of the status and identity of the dreamer, having nothing to do with Stoic quietude. And finally there is an inevitable involvement of the dreamer, the subject, who is anything but an ideal observer severed from the world. ${ }^{37}$

${ }^{36} \mathrm{Wu}$, The Butterfly as Companion, 176.

${ }^{37}$ Ibid., 177. 
It is important to note, however, that when $\mathrm{Wu}$ says that the subject is anything but an ideal observer, it does not mean that he no longer fulfills the notion of non-presence. This is simply to say that he becomes the unifier of all the segments of the whole. To clarify:

"Chuang Chou" (the knowing, indentifiable, nameable, phenomenal self) dreamed, then awoke, then wondered. In such dreaming, awakening, wondering, there is the real subject-self $(\mathrm{wu})$ that understands the mutual interchanges and distinctions of things. It is when I participate in these experiences that I come to understand: this is participatory knowledge. It is here that the things-in-themselves appear together (ch'i wu) and are known through being unknown. ${ }^{38}$

Though from a scholastic perspective this would seem to be highly contradictory, it is perfectly logical from a Daoist perspective in that one can be and not be at the very same time. One present segment can be occurring while it is kept in balance by the non-presence which allows it to exist, or as $\mathrm{Wu}$ says, "known through being unknown." This middle point for $\mathrm{Wu}$ is, if at all, an empty kind of substance which is able to shift and change accordingly to what the situation calls for, to radical interchanges in radial identity.

The self changes in wonderment over three changes, in which it obtains itself. First, there is change in knowledge, as described above. And then such uncertainty of knowledge empties right and wrong (yes and no) of content, because the criteria of yes and no change, and we do not have the unchanging universal right. Thirdly, this shift of perspectives culminates in an awakening. It is not an awakening that settles in true knowledge and certainty, but an awakening that wonders, an awakening to uncertainty. It is an awakening to the interchanges of things, including my identifiable self (wo). And it is precisely within this puzzlement over radical "interchanges" (of identities) "among things" (including my self), this awakening and

\footnotetext{
${ }^{38} \mathrm{Wu}$, The Butterfly as Companion, 185. Wu, like many other scholars of Zhuangzi, draws a distinction between the 吾 wu-self and 我 wo-self. For our convenience, it is worthwhile to look at 吾 wu-self as the central non-presence, while the 我 wo-self is a proper character that is Zhou.

(c) 2016 Christine Abigail L. Tan http://www.kritike.org/journal/issue 19/tan december2016.pdf ISSN 1908-7330
}

(c) BY-NC-ND 
recognition of the vicissitudes of actuality, that the continuity of the authentic self is obtained. The I continues as such precisely in its recognition of its own discontinuities as it participates in the interchanges among things. The original authentic self $(\mathrm{wu})$ is the yetto-begin-to-be my identifiable phenomenal self (wo), the primal subject that stops and stays at its not knowing, and knows such not-knowing. ${ }^{39}$

Thus, the dream in the butterfly does not, by any means, imply a sort of illusion nor delusion, but rather, "radical interchanges of identities among things including myself," and this very roaming and soaring of the subject, the wu-self, is what makes the radical equalizing of things possible, and what unites them, in their very singularity. The metaphysical implication thus noted by $\mathrm{Wu}$, is that:

This is to say that many tools have nothing to do with simple coherence. Each new situation imposes its own unity on our many concepts. Each situation uniquely regulates our many notions into a unity. Each situation differs from others, and can be construed from many perspectives (of many notions); our many notions grow into many kinds of them.

Thus the word "unique" is a plural; the one is many. The "one" is not idealistic, nor is the "many" simply conceptual; they are concrete situational "one" and "many." The more our notions are the richer will be our perception of many unique situations, whose unity life is, a concrete pluralistic monism.

Though Zhuangzi has a position of no position, it is from $\mathrm{Wu}$ that we understand non-presence not to mean as withdrawn relativism, but rather, a participatory kind of knowledge and of being, wherein one lives and acts in accordance to the unique nature of the situation, that is, in accordance with the Dao.

${ }^{39}$ Ibid., 206.

(C) 2016 Christine Abigail L. Tan 


\section{Zhuangzi's Perspectivism}

From what we can glean of Moeller's structure of presence as well as Wu's participatory knowledge and pluralistic monism as seen in the butterfly dream, Zhuangzi's perspectivism comes to light. To isolate this anecdote from the rest of Zhuangzi's philosophy, however, does not do the anecdote justice, for what exactly does this anecdote manifest when seen against the backdrop of his philosophy? In order to claim that Zhuangzi's Butterfly Dream is an instance of his perspectivism, manifesting Dao as a kind of pluralistic monism present within the entirety of his writings, we need to, at least, take a brief look into two themes that pervade Zhuangzi's philosophy: The unity and singularity of all things, as well as the process of becoming.

\section{The Unity and Singularity of Things}

Just as we have seen in the butterfly dream, what is singular is united, what is distinct is the same. The space beneath heaven or the sky is the unity of all things individual, where all things are in; and when one is at the center of a circle, one only sees what his radial perspective can grasp, but being at the center of the circle, one also necessarily understands that a different radius will lead to the same circumference, and is therefore just as valid. Indeed, Zhuangzi says:

When there is separation, there is coming together. When there is coming together, there is dissolution. All things may become one, whatever their state of being. Only he who has transcended sees this oneness. He has no use for differences and dwells in the constant. To be constant is to be useful. To be useful is to realize one's true nature. Realization of one's true nature is happiness. When one reaches happiness, one is close to perfection. So one stops, yet does not know that one stops. This is Tao. ${ }^{40}$

Thus, only the foolish worry about what is beyond his perspective, and only the foolish will push for others to see things the way he sees it. What Zhuangzi advocates thus, is in a sense, a holy stupidity, a sacred ignorance, where one does what nature calls for, what the situation calls for, and ultimately what Dao calls for. In the same way that the Guo Xiang

${ }^{40}$ Chuang-tzu, "Chapter Two: The Equality of All Things," in Inner Chapters, Amber Lotus ed., trans. by Gia-fu Feng and Jane English (San Francisco, CA: Amber Lotus Pub., 2000).

(c) 2016 Christine Abigail L. Tan http://www.kritike.org/journal/issue 19/tan december2016.pdf ISSN 1908-7330

(c) BY-NC-ND 
commentary insists on the singularity of each of the butterfly dream's character, we find in the Qiwulun, the same principle of ziran which Zhuangzi explains:

We are caught in the current and cannot return. We are tied up in knots like an old clogged drain; we are getting closer to death with no way to regain our youth. Joy and anger, sorrow and happiness, hope and fear, indecision and strength, humility and willfulness, enthusiasm and insolence, like music sounding from an empty reed or mushrooms rising from the warm dark earth, continually appear before us day and night. No one knows whence they come. Don't worry about it! Let them be! How can we understand it all in one day? ${ }^{41}$

How can we understand it all in one lifetime, even? For what we see and what we understand is always only a limited view, shaped by the circumstance we are caught in, but this limit, this singularity, is precisely how we are aware of the multiplicity of perspectives, where the One is many, and where many is One. Zhuangzi notes:

Every thing can be a "that;" every thing can be a "this." One man cannot see things as another sees them. One can only know things through knowing oneself. Therefore it is said, "'That' comes from 'this,' and 'this' comes from 'that'" - which means "that" and "this" give birth to one another. ${ }^{42}$

\section{The Process of Becoming}

The Singularity and Unity of all things thus, pre-supposes that every process has segments which is unique in their very own state. Just as in the process of water becoming ice, the same water will have different state of "iceness" at a specific time, and yet, as in a single thread, there is also a time when it is both water and ice at the same time, and so we find being and nonbeing to intertwine-as becoming. In the same way:

Life arises from death and death from life. What is inappropriate is seen by virtue of what is appropriate.

$$
\begin{aligned}
& { }^{41} \text { Ibid. } \\
& { }^{42} \text { Ibid. }
\end{aligned}
$$


There is right because of wrong, and wrong because of right. Thus, the sage does not bother with these distinctions but seeks enlightenment from heaven. So he sees "this," but "this" is also "that," and "that" is also "this." "That" has elements of right and wrong, and "this" has elements of right and wrong. Does he still distinguish between "this" and "that," or doesn't he? When there is no more separation between "this" and "that," it is called the still-point of Tao. At the still-point in the center of the circle one can see the infinite in all things. Right is infinite; wrong is also infinite. Therefore it is said, "Behold the light beyond right and wrong." 43

The very processes of the universe, of nature, is what unifies all things, but at the same, are also the same stages or phases which give them their individuality. Thus, now we find ourselves in full circle, and are reminded of a passage in the Dao De Jing, which goes:

Tao engenders One, One engenders Two, Two engenders Three, Three engenders the ten thousand things.

The ten thousand things carry shade and embrace sunlight. Shade and sunlight, yin and yang, Breath blending into harmony. ${ }^{44}$

In other words, it is in the very uniqueness of each of the "ten thousand things" that harmony and indeed, the very existence of a coherent reality, is made possible. We understand, therefore, that the phenomenal reality is kept orderly and in harmony though always in flux, by the nonchanging emptiness, that is, non-being at the still-point middle. Indeed, it is only by virtue of this still-point that the distinct coordinates come to be, and that the particular moments of phenomenal reality are made possible in dynamic but very distinctly divided members in a state of flux.

School of Humanities and Social Sciences, Nanyang Technological University, Singapore

${ }^{43}$ Ibid.

${ }^{44}$ Laozi, Tao Te Ching, Verse 42.

(c) 2016 Christine Abigail L. Tan

http://www.kritike.org/journal/issue 19/tan december2016.pdf

ISSN 1908-7330

(c) BY-NC-ND 


\section{References}

Allinson, Robert E. Chuang-Tzu for Spiritual Transformation: An Analysis of the Inner Chapters (Albany, NY: State University of New York Press, 1989).

Chuang Tzu, Chuang Tzu: Taoist Philosopher and Chinese Mystic, trans. by Herbert A. Giles (London: Unwin Paperbacks, 1926)

Chuang-tzu: The Seven Inner Chapters and Other Writings from the Book Chuang-tzu, trans. by A.C. Graham (London: George Allen and Unwin, 1981).

"Discussion on Making All Things Equal," in The Complete Works of Chuang Tzu, trans. by Burton Watson, in Terebress Asia Online (TAO), < http://terebess.hu/english/chuangtzu.html\#2>, 13 November 2014.

Inner Chapters, Amber Lotus ed., trans. by Gia-fu Feng and Jane English (San Francisco, CA: Amber Lotus Pub., 2000).

Han, Xiaoquiang, "Interpreting the Butterfly Dream," in Asian Philosophy, 19:1 (2009).

Jung, C.G., The Structure and Dynamics of the Psyche, vol. 8 of The Collected Works of C.G. Jung, $2^{\text {nd }}$ end. (London: Routledge, 2002).

Laozi, Tao Te Ching, trans. by Stephen Addis and Stanley Lombardo (Indianapolis: Hackett Pub. Co., 1993).

Lee, Jung H., "What Is It Like to Be a Butterfly? A Philosophical Interpretation of Zhuangzi's Butterfly Dream," in Asian Philosophy, 17:2 (2007).

Moeller, Hans-Georg, "Zhuangzi's 'Dream of the Butterfly': A Daoist Interpretation," in Philosophy East and West, 49:4 (1999).

Nagel, Thomas, "What Is It Like to Be a Bat?" in The Philosophical Review, 83:4 (1974).

$\mathrm{Wu}$, Kuang-Ming, The Butterfly as Companion: Meditations on the First Three Chapters of the Chuang Tzu (Albany, NY: State University of New York Press, 1990).

Yao, Zhihua, "'I Have Lost Me': Zhuangzi's Butterfly Dream," in Journal of Chinese Philosophy, 40:3-4 (2013).

(C) 2016 Christine Abigail L. Tan

http://www.kritike.org/journal/issue 19/tan december2016.pdf

ISSN 1908-7330

(cc) EY-NC-ND 